\section{cAMP promotes pancreatic $\beta$-cell survival via CREB-mediated induction of IRS2}

\author{
Ulupi S. Jhala, ${ }^{1}$ Gianluca Canettieri, ${ }^{1}$ \\ Robert A. Screaton, ${ }^{1}$ Rohit N. Kulkarni, ${ }^{4}$ \\ Stan Krajewski, ${ }^{2}$ John Reed, ${ }^{2}$ John Walker, ${ }^{3}$ \\ Xueying Lin, ${ }^{4}$ Morris White, ${ }^{4}$ and \\ Marc Montminy ${ }^{1,5}$
}

${ }^{1}$ The Salk Institute for Biological Studies, La Jolla, California 92037, USA; ${ }^{2}$ The Burnham Institute, La Jolla, California 92037, USA; ${ }^{3}$ The Genomics Institute of the Novartis Research Foundation, San Diego, California 92121, USA; ${ }^{4}$ Howard Hughes Medical Institute, The Joslin Diabetes Center, Harvard Medical School, Boston, Massachusetts 02215, USA

The incretin hormone GLP1 promotes islet-cell survival via the second messenger CAMP. Here we show that mice deficient in the activity of CREB, caused by expression of a dominant-negative A-CREB transgene in pancreatic $\beta$-cells, develop diabetes secondary to $\beta$-cell apoptosis. Remarkably, A-CREB severely disrupted expression of IRS2, an insulin signaling pathway component that is shown here to be a direct target for CREB action in vivo. As induction of IRS2 by cAMP enhanced activation of the survival kinase Akt in response to insulin and IGF-1, our results demonstrate a novel mechanism by which opposing pathways cooperate in promoting cell survival.

Supplemental material is available at http://www.genesdev.org.

Received March 26, 2003; revised version accepted May 13, 2003.

Feeding triggers a series of hormonal and nutrient cues that act cooperatively to promote insulin release from the pancreas. Elevations in blood glucose provide the most potent stimulus to insulin secretion; glucose oxidation in the pancreatic $\beta$-cell induces closure of $\mathrm{K}_{\mathrm{ATP}}$ channels and consequent calcium entry via voltage-sensitive L-type calcium channels (Newgard and McGarry 1995). Nearly half of the insulin secretory response relies additionally on glucagon-like peptide (GLP1) and other incretin hormones, which are synthesized and released into the circulation from enteroendocrine cells in the small intestine during feeding (Wang et al. 1995; Drucker 2003). Activation of the GLP1 receptor not only potentiates glucose-dependent insulin release but also pro-

[Keywords: CREB; $\beta$-cell; apoptosis; cAMP] ${ }^{5}$ Corresponding author.

E-MAIL montminy@salk.edu; FAX (858) 625-9045.

Article and publication are at http://www.genesdev.org/cgi/doi/10.1101/ gad.1097103. motes $\beta$-cell growth and survival by induction of the cAMP second messenger pathway (Hui et al. 2003).

cAMP stimulates the expression of numerous genes via the PKA-mediated phosphorylation of CREB and its paralogs ATF-1 and CREM at a single site corresponding to Ser 133 in CREB (Gonzalez and Montminy 1989). CREB family members (hereafter referred to as CREB) also undergo Ser 133 phosphorylation in neurons in response to calcium entry through voltage-sensitive L-type calcium channels, in part via the calcium/calmodulin dependent kinase IV (CamK IV; West et al. 2001). The ability of GLP1 receptor agonists to protect against $\beta$-cell apoptosis through a cAMP-dependent mechanism in rodent models of diabetes (Drucker 2003) prompted us to evaluate the role of CREB in this process. Here, we show that glucose and GLP1 converge on CREB, via calcium and cAMP pathways, respectively, to regulate $\beta$-cell gene expression. Using transgenic mice that are deficient in CREB activity in $\beta$-cells, we demonstrate a requirement for CREB function in glucose homeostasis and islet-cell survival. These studies may help to explain the therapeutic basis for GLP1 action in improving islet function in patients with type II diabetes.

\section{Results and Discussion}

\section{Glucose and GLP1 signaling pathways converge on CREB in the $\beta$-cell}

The ability of glucose and GLP1 to act cooperatively in promoting insulin secretion and islet gene expression (Susini et al. 1998) prompted us to evaluate the role of CREB in this process. Treatment of glucose-starved MIN6 insulinoma cells with high glucose (24 mM) stimulated rapid yet transient phosphorylation of CREB at Ser 133, as determined by Western blot assay with phospho (Ser 133)-specific antiserum (Fig. 1A). In keeping with the ability of glucose oxidation to promote closure of $\mathrm{K}_{\mathrm{ATP}}$ channels, both $\mathrm{KCl}$ depolarization and tolbutamide, a $\mathrm{K}_{\mathrm{ATP}}$ channel blocker, mimicked the effects of high glucose on Ser 133 phosphorylation (Fig. 1A).

Exposure of MIN6 cells to exendin-4, a long-acting agonist of GLP1, also promoted CREB phosphorylation, but with a delayed time course compared with depolarizing stimuli (30 min vs. $10 \mathrm{~min}$; Fig. 1A). The effect of exendin-4 on CREB phosphorylation proceeded via a distinct pathway from depolarizing stimuli; addition of Ltype calcium channel inhibitor (nifedipine) blocked both tolbutamide- and KCl-induced CREB phosphorylation, but had no effect on exendin-4 stimulation (Fig. 1B, left).

Consistent with their ability to activate CREB via distinct pathways, exendin- 4 and tolbutamide stimulated both higher levels of Ser 133 phosphorylation and endogenous CREB target gene expression than either agent alone (Fig. 1B, right, 1C). Indeed, cooperative induction of NR4A2, an immediate-early CREB target gene (Conkright et al. 2003), by exendin-4 and tolbutamide was blocked by infection of MIN6 cells with adenovirus expressing the dominant-negative CREB inhibitor A-CREB (Fig. 1C; Ahn et al. 1998). A-CREB contains an acidic stretch of amino acids, fused to the CREB leucinezipper domain, that extends the dimerization interface with and blocks binding of cellular CREB but not other 
A

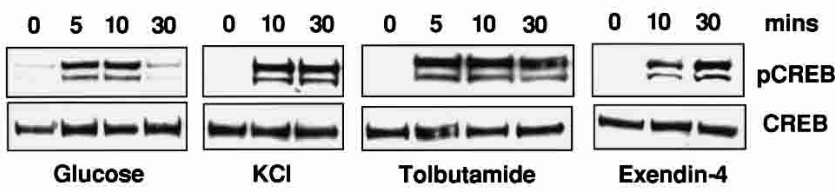

B

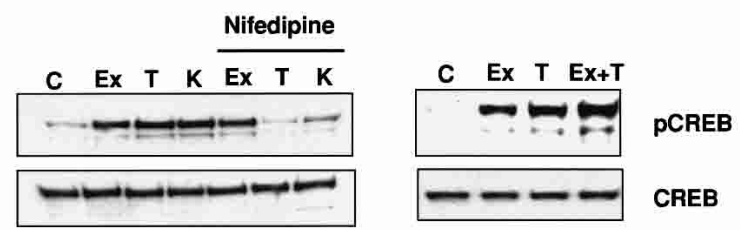

C

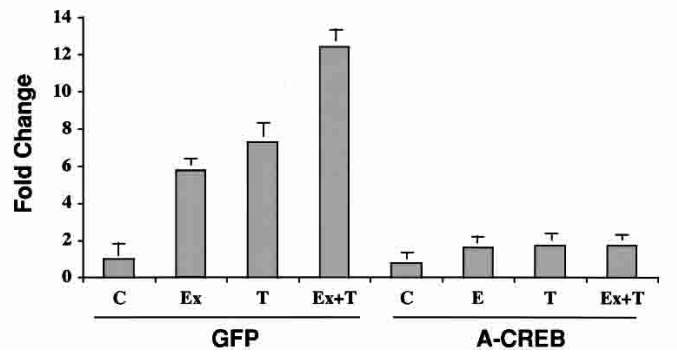

Figure 1. Cooperative effects of glucose and GLP-1 signaling on CREB activation. (A) Western blot assay of phospho (Ser 133) and total CREB levels in MIN6 cells following stimulation with high glucose, $\mathrm{KCl}$ depolarization, $\mathrm{K}_{\mathrm{ATP}}$ channel antagonist tolbutamide, or GLP1 agonist exendin-4. $(B$, left $)$ Effect of L-type calcium channel antagonist nifedipine on CREB phosphorylation in MIN6 cells following treatment (30 min) with exendin-4 (Ex), tolbutamide (T), and $\mathrm{KCl}(\mathrm{K})$. (Right) Additive effect of glucose and GLP1 signaling on CREB phosphorylation. Cells were treated with the GLP-1 analog exendin-4 and tolbutamide, either individually or together, and analyzed for CREB Ser 133 phosphorylation. (C) Quantitative PCR analysis of endogenous CREB target gene (NR4A2) expression in response to glucose, tolbutamide, and exendin-4, individually and in combination. Effect of dominant-negative CREB (A-CREB) adenovirus or control (GFP) adenovirus infection on NR4A2 expression.

bZIP family members to DNA. Taken together, these results indicate that glucose and GLP1 signaling converge on CREB via calcium and cAMP pathways, respectively, to regulate islet gene expression.

\section{Disrupting CREB activity in $\beta$-cells causes diabetes}

To evaluate the importance of CREB for $\beta$-cell function, we characterized transgenic mice that express an $A$-CREB transgene under control of the $\beta$-cell-specific rat insulin promoter-1 $(R I P)$. When transfected into MIN6 insulinoma cells, the A-CREB polypeptide efficiently blocked cAMP-dependent activation of a cotransfected CRE reporter (Fig. 2A), indicating that the transgene was functional.

We identified three independent RIP A-CREB founder lines by PCR analysis. Expression of the $A-C R E B$ transgene was confirmed by quantitative PCR and Western blot assays of islet lysates from RIP A-CREB mice (data not shown; Fig. 2A, right). A-CREB-expressing mice were indistinguishable from wild-type littermates at birth but showed gradual impairment in glucose homeostasis after weaning, and became overtly diabetic at 12-14 wk (Fig. 2B). All three transgenic lines exhibited glucose intolerance in adulthood, although the onset and severity of hyperglycemia differed for each line. Consistent with a relative deficiency in insulin release from the pancreas,
RIP A-CREB animals displayed glucose intolerance at 7-8 wk (Fig. 2C). Indeed, ambient serum insulin levels were $30 \%$ lower in RIP A-CREB versus control littermates at $8 \mathrm{wk}$ and $70 \%$ lower at $12 \mathrm{wk}$, suggesting that the hyperglycemia in these mice reflects a primary defect in $\beta$-cell function (Fig. 2D).

The disparity in serum insulin levels between transgenic and control littermates prompted us to perform immunohistochemical and morphometric studies on pancreatic sections. Staining for the $\beta$-cellspecific proteins Glut-2 and PDX-1 as well as insulin was comparable in pancreatic sections from wildtype mice and diabetic 12-14-wk RIP A-CREB littermates, indicating that loss of CREB activity does not impair the expression of genes that are critical for glucose-stimulated insulin secretion (Supplementary Fig. $1 \mathrm{a}, \mathrm{b})$. In contrast, $\beta$-cell mass in RIP A-CREB mice was reduced $40 \%$ at $8 \mathrm{wk}$, and further reduced by $70 \%$ at 12 wk relative to control littermates (Fig. $3 \mathrm{~A}, \mathrm{~B}$, left panels). Confirming a specific effect of ACREB on $\beta$-cells, non- $\beta$-cell mass (somatostatin/glucagon-producing cells) was unaffected in transgenic mice (Fig. 3A,B, right panels).

The loss of $\beta$-cell mass-without detectable change in expression of insulin, Glut-2, and PDX-1prompted us to examine the effect of A-CREB on islet-cell survival. Activation of the apoptotic program was detectable in pancreatic sections from RIP ACREB mice as early as $5 \mathrm{wk}$ by staining for activated caspase- 3 and at 10 wk for caspase-6 (Fig. 3C). Indeed, morphologic characteristics of apoptosis, such as nuclear condensation and fragmentation, were evident in islet $\beta$-cells from 8 -week-old transgenic mice by electron microscopic analysis (Fig. 3D), further supporting the idea that CREB is required for isletcell survival.

CREB appeared to promote islet-cell survival in the absence of systemic contributions; infection of MIN6 cells with A-CREB adenovirus induced apoptosis threefold to fourfold over control GFP-infected cells by caspase assay (Supplementary Fig. 2). To determine the mechanism by which CREB protects against islet-cell death, we performed gene profiling studies on MIN6 cells infected with A-CREB or control GFP adenovirus and then treated them for $1 \mathrm{~h}$ with forskolin. Notably, expression of the antiapoptotic $B c l 2$ gene, which has been shown to mediate survival effects of CREB in neurons (Riccio et al. 1999), was not altered either by cAMP treatment or by A-CREB adenovirus in MIN6 cells (data not shown). The most highly regulated gene on this list was the insulin receptor substrate 2 (IRS-2)—a key intermediate in the insulin/IGF signal transduction pathway, the expression of which is critical for $\beta$-cell function (Withers et al. 1998).

\section{CREB potentiates insulin/IGF signaling}

The ability of cAMP to induce IRS2 expression prompted us to evaluate further the role of CREB in this process. Exposure of MIN6 cells and primary human islets to forskolin induced accumulation of IRS2 protein fourfold to fivefold after $12 \mathrm{~h}$ but had no effect on levels of IRS1 (Fig. 4A; Supplementary Fig. 3a). Infection with A-CREB adenovirus almost completely blocked IRS2 induction by forskolin, demonstrating the importance of CREB in this process (Fig. 4A). In line with their effects on CREB phos- 
A
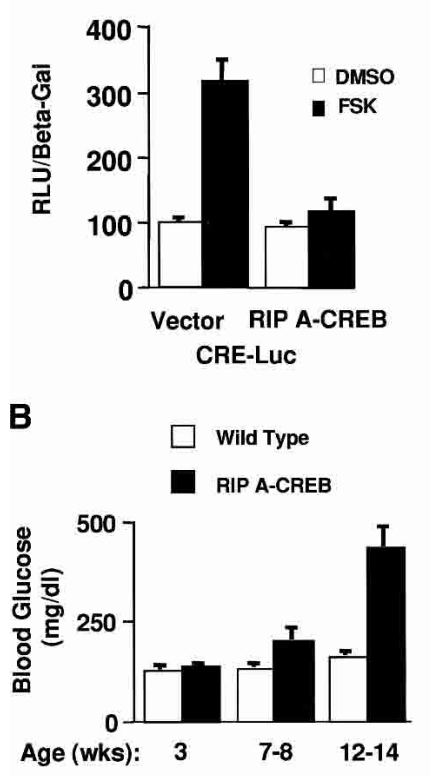

C
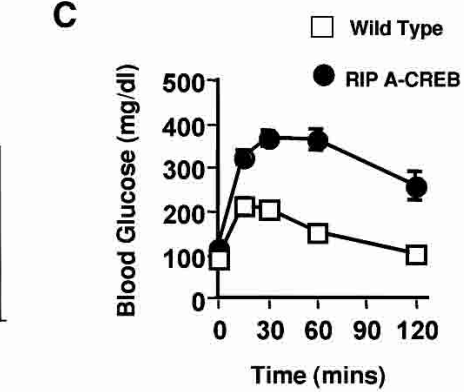

D
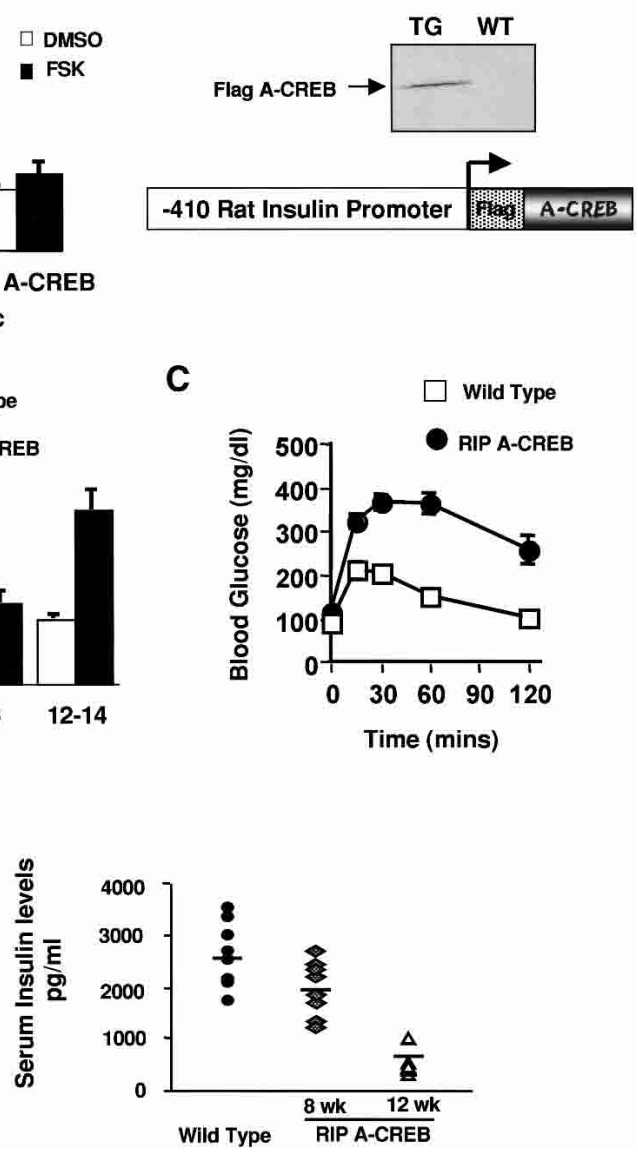

Figure 2. RIP A-CREB transgenic mice develop diabetes. (A) Schematic and transient transfection assay of the RIP A-CREB expression vector in HIT-T15 insulinoma cells using the somatostatin CRE luciferase reporter. (Right) Western blot of islet lysates from wild-type and RIP A-CREB mice using anti-Flag tag antiserum. (B) Ambient glucose levels in RIP A-CREB transgenic mice $(n=15)$ compared with wild-type littermates $(n=12)$ at $3,7-8$, or $12-14$ wk of age. (C) Glucose tolerance curves of RIP A-CREB and wild-type mice at $8 \mathrm{wk}$. Glucose levels were monitored at the times indicated after intraperitoneal injection $(2 \mathrm{~g} / \mathrm{kg})$ of glucose. $(D)$ Serum insulin levels in wild-type $(2694 \pm 205 \mathrm{pg} / \mathrm{mL} ; n=8)$ compared with A-CREB transgenic mice at $8 \mathrm{wk}$ $(1930 \pm 211 \mathrm{pg} / \mathrm{mL} ; n=7)$, and $12 \mathrm{wk}(462 \pm 48 \mathrm{pg} / \mathrm{mL} ; n=8)$.

phorylation, tolbutamide and exendin-4 also increased IRS2 protein levels in MIN6 cells by Western blot analysis (Supplementary Fig. 3a).

Inspection of the mouse IRS2 promoter revealed a consensus CRE half-site (TGACG) at -671 that was capable of binding CREB protein in gel mobility shift assays (Supplementary Fig. 3b). No other consensus CREs were detected within $1 \mathrm{~kb}$ upstream of the -671 CRE half-site in the IRS2 promoter. In transient transfection assays, forskolin treatment induced an IRS2-luciferase reporter plasmid 4.5-fold, and cotransfection of A-CREB expression vector blocked this effect (Fig. 4B). Moreover, in chromatin immunoprecipitation assays the IRS2 promoter was efficiently recovered from immunoprecipitates of CREB prepared from MIN6 cells with anti-CREB antiserum 244, but not with nonspecific IgG (Fig. 4C). Consistent with the ability of A-CREB to inhibit IRS2 promoter activity, IRS2 protein levels were markedly reduced in RIP A-CREB mice compared with control lit- termates both by Western blot assay of islet lysates and by immunohistochemical analysis (Fig. 4D). Taken together, these results indicate that the IRS2 gene is a direct target for CREB action in vivo.

IRS2 is thought to promote islet-cell survival by mediating phosphorylation of Akt at Thr 308 in response to insulin and IGF1 signaling (Withers et al. 1998; Tuttle et al. 2001). The ability of cAMP to induce IRS2 expression prompted us to examine whether prior exposure of islet cells to cAMP agonist potentiates Akt activation in response to IGF1. Treatment of MIN6 cells with IGF1 alone induced Thr 308 phosphorylation of Akt, whereas forskolin had little effect (Fig. 4E). However, IGF1-dependent phosphorylation of Akt1 at Thr 308 was substantially enhanced in cells pretreated with forskolin (Fig. 4E). Thr 308 phosphorylation of Akt1 was blocked by prior infection of MIN6 cells with ACREB but not control GFP adenovirus, confirming the importance of CREB in this process (Fig. 4E). Together, these data indicate that induction of IRS2 by CREB potentiates insulin/IGF1 signaling in $\beta$-cells.

cAMP and growth factor signaling pathways have long been thought to act in opposing fashion in the regulation of metabolism and cellular proliferation (Graves et al. 1993; Wu et al. 1993). Our results reveal an unexpected and novel mechanism by which cAMP exerts a permissive effect on growth factor signaling via CREB. These data suggest that the therapeutic benefit of GLP1 analogs in promoting islet-cell function is due in part to activation of IRS2 via CREB.

The ability of the cAMP/CREB signaling pathway to induce IRS2 but not IRS1 expression is noteworthy with respect to the phenotypes of mice harboring their respective gene knockouts. IRS $2^{-/-}$mice display a marked decrease in $\beta$-cell mass caused by poor islet growth and survival (Withers et al. 1998, 1999; Kubota et al. 2000). In contrast, IRS1-/- mice display increased $\beta$-cell mass and are able to compensate for hepatic insulin resistance (Bruning et al. 1997; Kulkarni et al. 1999|, perhaps in part reflecting the preferential induction of IRS2 by CREB in response to feeding.

In addition to its role in the $\beta$-cell, CREB has been shown to function as an important survival factor for neuronal cells (Lonze et al. 2002; Mantamadiotis et al. 2002). In sympathetic neurons, CREB appears to mediate neurotrophin-dependent survival via induction of the antiapoptotic Bcl-2 gene (Riccio et al. 1999). Mice with a combined knockout in CREB and CREM genes in brain show selective age-related loss of certain neuronal populations, although Bcl-2 expression in this setting as well as in RIP A-CREB mice is normal (Mantamadiotis et al. 2002). In this regard, it will be of interest to determine whether CREB promotes cell survival in other cell types by induction of IRS2.

\section{Materials and methods}

Generation of RIP A-CREB transgenic mice

The 5 '-flanking rat insulin 1 promoter from -410 bp to +10 bp was cloned into the multicloning site of pCAT basic (Promega Corp.). The entire transgene consisted of the -410 rat insulin promoter, the SV40 small T antigen intron, the coding region of Flag A-CREB, and the SV40 large T 
A

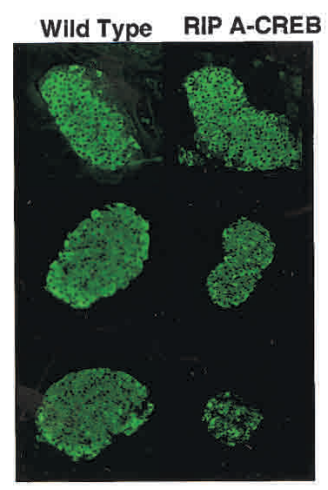

B

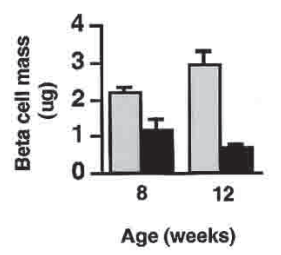

C
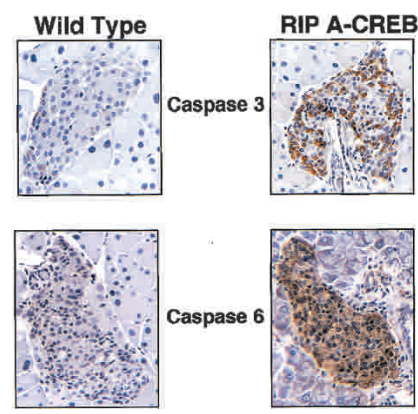

Wild Type RIP A-CREB

3 weeks

7-8 weeks

12-14 weeks
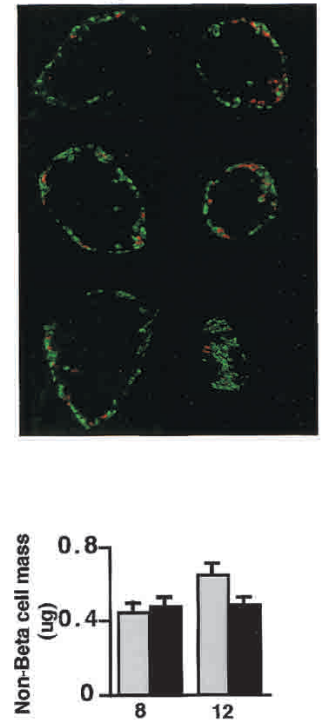

Age (weeks)

D

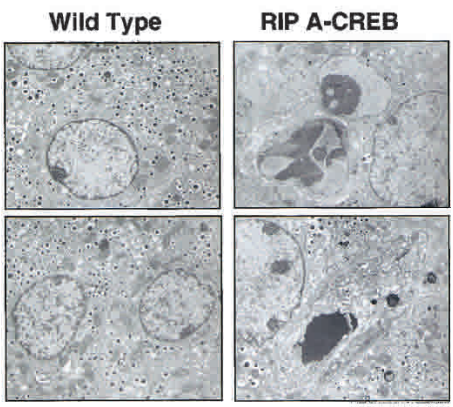

Figure 3. Progressive loss of islet-cell mass and cellular apoptosis in RIP A-CREB transgenic mice. (A) Immunohistochemical staining of pancreatic sections from transgenic and control mice at 3,8 , and 12 wk of age using antiinsulin (green) antibodies (left) or somatostatin (green) and glucagon (red) antisera (right). (B) Bar graph showing relative mass in transgenic and control mice by morphometric analysis. (C) Immunocytochemical staining for activated caspases in pancreatic sections of wild-type and A-CREB transgenic littermates. Staining for caspase-3 performed on 5-week-old mice, and staining for caspase-6 performed on 10-week-old mice. $(D)$ Electron microscopic analysis of islets from wild-type and A-CREB transgenic mice. (Left) Normal $\beta$-cells with evenly distributed heterochromatin and characteristic insulin granules (magnification 11,360x). (Right, top) Islet $\beta$-cells from A-CREB mice in early stages of apoptosis with redistribution of chromatin into electron dense aggregates (magnification 14,560x). (Right, bottom) End-stage apoptosis (magnification $11,360 \times$ ) characterized by progressive cytoplasmic vacuolation and nuclear fragmentation.

poly(A) signal. Three transgenic founders numbered 400, 600, and 700 were identified with PCR and outbred into a C57Bl6 background. Transgenic males from each line showed progressive deterioration in glucose homeostasis; females appeared normal and were not further characterized.

\section{Cell culture and treatments}

MIN6 cells (passages 22-30) were grown in Dulbecco's modified Eagle's Medium containing $25 \mathrm{mM}$ glucose supplemented with $10 \%$ fetal bovine serum, $100 \mu \mathrm{g} / \mathrm{mL}$ streptomycin, 100 units $/ \mathrm{mL}$ penicillin sulfate, and 50 $\mu \mathrm{M} \beta$-mercaptoethanol. Cells were incubated overnight in medium containing $4 \mathrm{mM}$ glucose prior to treatment. Cells were treated in $24 \mathrm{mM}$ glucose plus $45 \mathrm{mM} \mathrm{KCl}, 100 \mu \mathrm{M}$ tolbutamide, $10 \mathrm{nM}$ exendin-4, $10 \mu \mathrm{M}$ forskolin, or $10 \mu \mathrm{M}$ nifedipine where indicated and for the times specified.

\section{Histological analysis}

Pancreata were dissected from anesthetized mice, and fixed in chilled Bouins solution or $2 \%$ paraformaldehyde. The pancreata were fixed for 8-12 $\mathrm{h}$ and paraffin-embedded, and $5-\mu \mathrm{m}$ sections were generated. For immunofluorescence, deparaffinized sections were treated with antigen retrieval buffer ( $\mathrm{pH} 10$; Dako USA) prior to being processed. Sections were immunostained using anti-PDX-1 cocktail, anti-insulin (Linco), anti-glucagon (Sigma), and anti-Glut-2 (gift of B. Thorens, University of Lausanne, Lausanne, Switzerland), and somatostatin (Dako, USA). Detection was performed using Cy2- and Cy3-conjugated secondary antibodies (Jackson Immunoresearch). Sections were photographed using a DeltaVision deconvolution microscope (Applied Precision). For immunohistochemistry, sections were stained with Anti-Activated Caspase 3 and Caspase 6, Anti-IRS2 (Upstate) antibodies using Dako's antibody diluent, and the Envision plus secondary antibody. For color development, DAB chromogen (Dako) was used, with Myers hematoxylin (diluted 1:1) for counterstaining.

\section{Electron microscopy}

Pooled isolated islets from wild-type and RIP A-CREB transgenic mice were fixed at $4{ }^{\circ} \mathrm{C}$ overnight in $2.5 \%$ glutaraldehyde in $0.1 \mathrm{M}$ phosphate buffer ( $\mathrm{pH} 7.4)$, then washed and further fixed in $2 \%$ $\mathrm{OsO}_{4}$. The fixed islets were embedded in epoxy resin, sectioned (400-500 A thickness), stained with saturated uranyl acetate and lead citrate, and examined using a Philips 301 transmission electron microscope. EM studies were conducted by the advanced microscopy core facility (DERC) at the Joslin Diabetes Center.

\section{Measurements of islet-cell mass}

Three serial sections per pancreas, separated by a minimum of 70 $\mu \mathrm{m}$, were stained with anti-insulin or a cocktail of non- $\beta$-cell islet hormone antisera. $\beta$-cell and non- $\beta$-cell mass was assessed using point counting morphometry as described (Bonner-Weir et al. 1989; Michael et al. 2000).

\section{Glucose tolerance tests}

Glucose tolerance tests were performed on animals that had been fasted for $16 \mathrm{~h}$. Animals were injected intraperitoneally with 2 $\mathrm{g} / \mathrm{kg}$ body weight of glucose, and glucose levels were measured from tail vein blood collected before and 15, 30, 60, and $120 \mathrm{~min}$ after injection. Glucose measurements were performed using a Lifescan One Touch Glucometer.

\section{Blood insulin measurements}

Serum insulin levels were measured by ELISA (Alpco), by the specialized Assay Core facility (DERC) at The Joslin Diabetes Center. Values were reported in picograms per milliliter \pm the standard error of the mean.

\section{Adenovirus infection}

MIN6 cells were cultured to $70 \%$ confluence and infected with GFP control or A-CREB adenovirus (Herzig et al. 2001). The appropriate titer for both viruses was determined by the addition of various dilutions of each adenovirus to MIN6 cells cultured in six-well plates to $70 \%$ confluence. For caspase assays, MIN6 cells were harvested and subjected to one freeze-thaw cycle (dry ice/ $37^{\circ} \mathrm{C}$. After clarifying by centrifugation at $13,000 \mathrm{~g}$ at $4^{\circ} \mathrm{C}$ for $10 \mathrm{~min}, 20 \mu \mathrm{g}$ of soluble extract from each sample was incubated with $20 \mu \mathrm{M}$ Ac-DEVD-AFC (Alexis Biochemicals) at $37^{\circ} \mathrm{C}$. DEVDase activity is reported as the $V_{\max }$ for the 15-min reactions (relative light units per minute).

Plasmid construction and transient transfections

For plasmid construction and transient transfections, $1.3 \mathrm{~kb}$ of the IRS2 5 '-flanking region was subcloned into a PXP2 vector driving the luciferase reporter. HIT-T15 cells (SMS-Luc) or 293T cells (IRS2-Luc) were transfected with 100-400 ng of reporter plasmid together with $100 \mathrm{ng}$ of RSV- $\beta$ Gal internal control, and RIP A-CREB or CMV A-CREB (100 ng), 
A

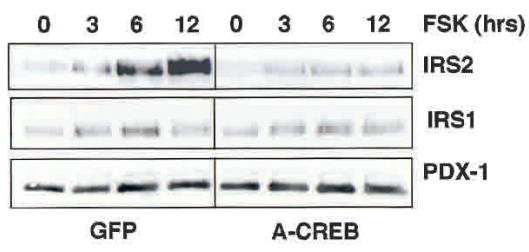

B

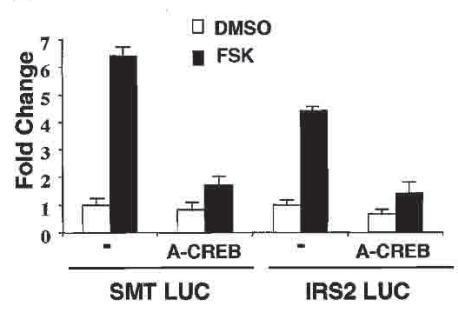

C

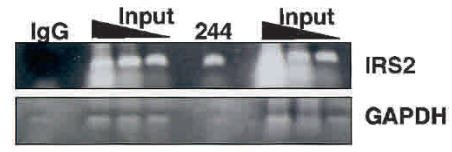

D
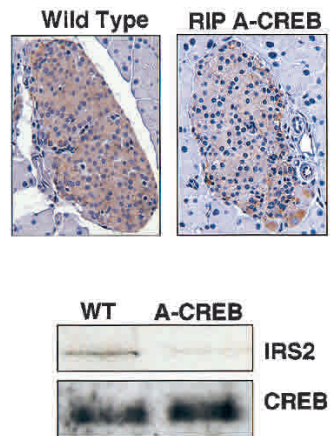

Figure 4. CREB promotes insulin/IGF signaling via induction of IRS2. $(A)$ Western blot analysis of IRS1 and IRS2 levels in MIN-6 cells treated with forskolin for increasing times in serum-supplemented medium. Cells were infected with A-CREB or control GFP adenovirus as indicated. (B) Transient transfection assay of $293 \mathrm{~T}$ cells with IRS2 promoter construct or control somatostatin CRE luciferase plasmid. Cells treated with forskolin or DMSO vehicle. Cotransfection with A-CREB expression plasmid is indicated. $(C)$ Chromatin immunoprecipitation assay of the IRS2 promoter using CREB 244 antiserum. Presence of the IRS2 promoter or negative control GAPDH in CREB immunoprecipitates determined by PCR amplification of anti-CREB or control IgG immunoprecipitates. (D) IRS2 expression is disrupted in A-CREB transgenic mice. (Top) Immunohistochemical staining of pancreatic sections from wild-type and RIP A-CREB transgenic mice using anti-IRS2 antiserum. (Bottom) Western blot assay of islet-cell extracts from wild-type and A-CREB mice using anti-IRS2 antiserum. Comparable levels of CREB protein in transgenic and wild-type lysates. (E) cAMP-dependent induction of IRS-2 potentiates growth factor signaling to Akt. Effect of IGF1 on Akt phosphorylation at Thr 308 in cells pretreated with forskolin or vehicle under serum-starved conditions for 8 h. Effect of A-CREB on IGF-stimulated Akt Thr 308 phosphorylation.

using Lipofectin reagent (Invitrogen). Cellular extracts were measured for Luciferase activity (Turner Biosystems Luminometer) and normalized using $\beta$-galactosidase.

Western blotting

Cellular lysates for Western blotting were prepared using SDS-urea lysis buffer containing phosphatase and protease inhibitors. Primary antibodies used for Western analysis include anti-CREB (244), anti-phosphoCREB (5322), anti-Flag (M2-Sigma), anti-PDX-1, anti-IRS2 (Upstate), antiIRS-1 (kindly provided by Ron Kahn, The Joslin Diabetes Center, Boston, MA), anti-Akt, and anti-phospho308-Akt (Cell Signaling).

Quantitative PCR

Cells were infected with A-CREB or GFP adenovirus for $48 \mathrm{~h}$, treated as indicated for $1 \mathrm{~h}$, and processed with an RNeasy Kit (QIAGEN). Reverse transcription and Taqman PCR were performed as described (Herzig et al. 2001), using primers specific for NR4A2, IRS2, and L32.

Chromatin immunoprecipitation assays

ChIP assays were performed as previously described (Canettieri et al. 2003). PCR was performed with primers complementary to the IRS2 promoter region (forward -1244/-1225, reverse -1092/ -1106 ) or to the GAPDH gene (forward 586/605, reverse 1037) 1018) as control, by using the GC-rich PCR Kit (Roche).

Gene profiling analysis

Gene profiling analysis of MIN6 RNA was performed using the Affymetrix high-density oligonucleotide array mouse U74A chip. Intensity values were obtained for two independent experiments.

\section{Acknowledgments}

We thank Ergeng Hao for help with islet isolation and Keyong Du for helpful discussion and advice. This work is supported by NIH grants GM37828 and DK49777 to M.M. and DK43828 to M.F.W., and by the Hillblom Foundation. G.C. and X.L. are supported by the Juvenile Diabetes Foundation fellowship. R.N.K. is the recipient of a Clinician Scientist Award.

The publication costs of this article were defrayed in part by payment of page charges. This article must therefore be hereby marked "advertisement" in accordance with 18 USC section 1734 solely to indicate this fact.

\section{References}

Ahn, S., Olive, M., Aggarwal, S., Krylov, D., Ginty, D.D., and Vinson, C. 1998. A dominant-negative inhibitor of CREB reveals that it is a general mediator of stimulus-dependent transcription of c-fos. Mol. Cell. Biol. 18: 967-977.

Bonner-Weir, S., Deery, D., Leahy, J.L., and Weir, G.C. 1989 Compensatory growth of pancreatic $\beta$-cells in adult rats after short-term glucose infusion. Diabetes 38: 49-53.

Bruning, J.C., Winnay, J., Bonner-Weir, S., Taylor, S.I., Accili, D., and Kahn, C.R. 1997. Development of a novel polygenic model of NIDDM in mice heterozygous for IR and IRS-1 null alleles. Cell 88: 561-572.

Canettieri, G., Morantte, I., Guzman, E., Asahara, H., Herzig, S., Anderson, S.D., Yates, J.R., and Montminy, M. 2003. Attenuation of a phosphorylation-dependent activator by an HDACPP1 complex. Nat. Struct. Biol. 10: 175-181.

Conkright, M.D., Guzmán, E., Flechner, L., Su, A.I., Hogenesch, J., and Montminy, M. 2003. Genome wide analysis of CREB target genes reveals a core promoter requirement for cAMP responsiveness. Mol. Cell 11: 1101-1108.

Drucker, D.J. 2003. Glucagon-like peptides: Regulators of cell proliferation, differentiation, and apoptosis. Mol. Endocrinol. 17: $161-171$.

Gonzalez, G.A. and Montminy, M.R. 1989. Cyclic AMP stimulates somatostatin gene transcription by phosphorylation of CREB at serine 133. Cell 59: 675-680.

Graves, L., Bornfeldt, K., Raines, E., Potts, B., Macdonald, S., Ross, R., and Krebs, E. 1993. Protein kinase A antagonizes platelet-derived growth factor-induced signaling by mitogenactivated protein kinase in human arterial smooth muscle cells. Proc. Natl. Acad. Sci. 90: 10300-10304.

Herzig, S., Long, F., Jhala, U.S., Hedrick, S., Quinn, R., Bauer, A., Rudolph, D., Schutz, G., Yoon, P., Puigserver, C., et al. 2001. CREB regulates hepatic gluconeogenesis through the coactivator PGC-1. Nature 413: $179-183$.

Hui, H., Nourparva, A., Zhao, X., and Perfetti, R. 2003. Glucagon-Like peptide-1 inhibits apoptosis of insulin-secreting cells via a cyclic 5'adenosine monophosphate-dependent protein kinase A- and a phosphatidylinositol 3-kinase-dependent pathway. Endocrinology 144: 1444-1455.

Kubota, N., Tobe, K., Terauchi, Y., Eto, K., Yamauchi, T., Suzuki, R., Tsubamoto, Y., Komeda K., Nakano, R., Miki, H., et al. 2000. Disruption of insulin receptor substrate 2 causes type 2 diabetes because of liver insulin resistance and lack of compensatory $\beta$-cell hyperpla- 
Jhala et al.

sia. Diabetes 49: 1880-1889.

Kulkarni, R.N., Winnay, J.N., Daniels, M., Bruning, J.C., Flier, S.N., Hanahan, D., and Kahn, C.R. 1999. Altered function of insulin receptor substrate-1-deficient mouse islets and cultured $\beta$-cell lines. J. Clin. Invest. 104: R69-R75.

Lonze, B.E., Riccio, A., Cohen, S., and Ginty, D.D. 2002. Apoptosis, axonal growth defects, and degeneration of peripheral neurons in mice lacking CREB. Neuron 34: 371-385.

Mantamadiotis, T., Lemberger, T., Bleckmann, S.C., Kern, H., Kretz, O., Martin Villalba, A., Tronche, F., Kellendonk, C., Gau, D., Kapfhammer, J., et al. 2002. Disruption of CREB function in brain leads to neurodegeneration. Nat. Genet. 31: 47-54.

Michael, M.D., Kulkarni, R.N., Postic, C., Previs, S.F., Shulman, G.I., Magnuson, M.A., and Kahn, C.R. 2000. Loss of insulin signaling in hepatocytes leads to severe insulin resistance and progressive hepatic dysfunction. Mol. Cell 6: 87-97.

Newgard, C.B. and McGarry, J.D. 1995. Metabolic coupling factors in pancreatic $\beta$-cell signal transduction. Annu. Rev. Biochem. 64: 689719.

Riccio, A., Ahn, S., Davenport, C.M., Blendy, J.A, and Ginty, D.D. 1999. Mediation by a CREB family transcription factor of NGF-dependent survival of sympathetic neurons. Science 286: 2358-2361.

Susini, S., Rocheb, E., Prentkib, M., and Schlegel, W. 1998. Glucose and glucoincretin peptides synergize to induce c-fos, c-jun, junB, zif-268, and nur-77 gene expression in pancreatic $\beta($ INS-1) cells. FASEB J. 12: $1173-1182$.

Tuttle, R.L., Gill, N.S., Pugh, W., Lee, J.P., Koeberlein, B., Furth, E.E., Polonsky, K.S., Naji, A., and Birnbaum, M.J. 2001. Regulation of pancreatic $\beta$-cell growth and survival by the serine/threonine protein kinase Akt1/PKB $\alpha$. Nat. Med. 7: 1133-1137.

Wang, Z., Wang, R.M., Owji, A.A., Smith, D.M., Ghatei, M.A., and Bloom, S.R. 1995. Glucagon-like peptide-1 is a physiological incretin in rat. J. Clin. Invest. 95: 417-421.

West, A.E., Chen, W.G., Dalva, M.B., Dolmetsch, R.E., Kornhauser, J.M., Shaywitz, A.J., Takasu, M.A., Tao, X., and Greenberg, M.E. 2001. Calcium regulation of neuronal gene expression. Proc. Natl. Acad. Sci. 98: 11024-11031.

Withers, D.J., Gutierrez, J.S., Towery, H., Burks, D.J., Ren, J.M., Previs, S., Zhang, Y., Bernal, D., Pons, S., Shulman, G.I., et al. 1998. Disruption of IRS- 2 causes type 2 diabetes in mice. Nature 391: 900-904.

Withers, D.J., Burks, D.J., Towery, H.H., Altamuro, S.L., Flint, C.L., and White, M.F. 1999. Irs-2 coordinates Igf-1 receptor-mediated $\beta$-cell development and peripheral insulin signalling. Nat. Genet. 23: 32-40.

Wu, J., Dent, P., Jelinek, T., Wolfman, A., Weber, M., and Sturgill, T. 1993. Inhibition of the EGF-activated MAP kinase signaling pathway by adenosine 3',5'-monophosphate. Science 262: 1065-1067. 


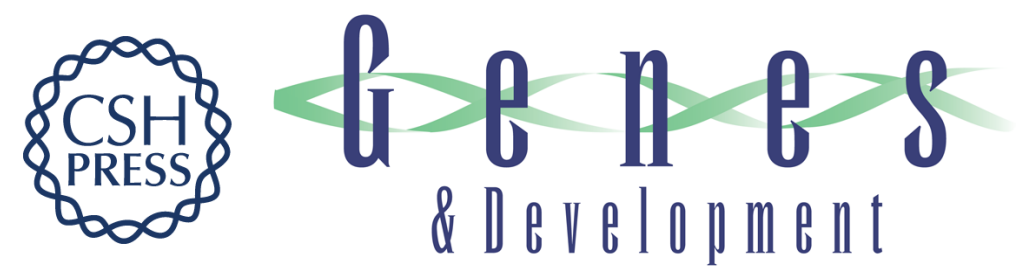

\section{cAMP promotes pancreatic $\beta$-cell survival via CREB-mediated induction of IRS2}

Ulupi S. Jhala, Gianluca Canettieri, Robert A. Screaton, et al.

Genes Dev. 2003, 17:

Access the most recent version at doi:10.1101/gad.1097103

Supplemental http://genesdev.cshlp.org/content/suppl/2003/06/13/17.13.1575.DC1
Material

References This article cites 22 articles, 7 of which can be accessed free at:

http://genesdev.cshlp.org/content/17/13/1575.full.html\#ref-list-1

License

Email Alerting

Receive free email alerts when new articles cite this article - sign up in the box at the top

Service

right corner of the article or click here.

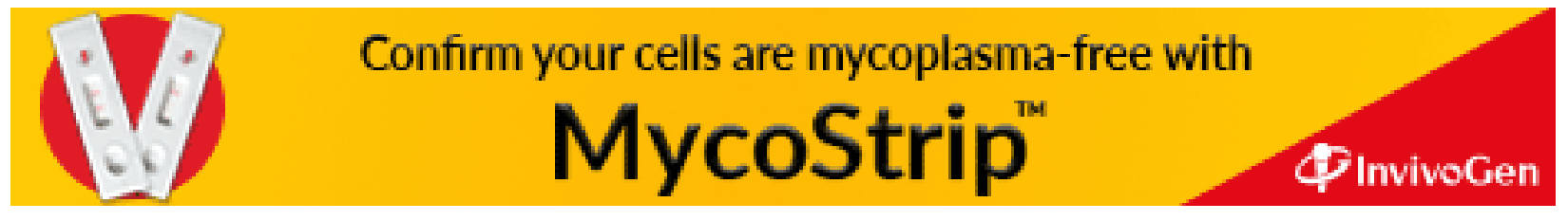

